\title{
Exploring the response of rice (Oryza sativa) leaf to gibberellins: a proteomic strategy
}

\author{
Xiaoqin Wang ${ }^{1,2}$, Feng $\mathrm{Han}^{3}$, Mingfeng Yang ${ }^{1}$, Pingfang Yang ${ }^{4}$ and Shihua Shen ${ }^{2 *}$
}

\begin{abstract}
Background: Gibberellins (GAs) are plant-specific hormones that play a central role in the regulation of growth and development with respect to environmental variability. Plants respond to GAs signal through various biochemical and physiological processes. To better understand the response for GA signal, we carried out a proteomic study in rice (Oryza sativa L. spp. japonica) leaf.

Results: Through two-dimensional gel electrophoresis (2-DE) and mass spectroscopy analysis, we identified 61 proteins as GA-responsive. These proteins were annotated in various biological functions, such as signal transduction and cell growth/division, photosynthesis and energy metabolism, protein stability and defense. Among these, photosynthetic proteins decreased while many catabolic proteins increased. In addition, GA up-regulated a variety of cell growth/division, protein stability and defense proteins such as cell division cycle protein 48 , molecular chaperones, and catalases.
\end{abstract}

Conclusion: This is the first report that cell division cycle protein 48 may be responsible for leaf expansion after leaf sensing GA signal. The results presented here provide new insight into the mechanism of rice leaf in response to GA signal.

Keywords: Gibberellins; Proteome; Rice leaf; Leaf expansion; cdc48

\section{Background}

As a sessile eukaryote, plants have evolved a fine mechanism that makes them sense and respond to the exterior-environmental changes accurately. For a long time, it was presumed that there are some specific substances that not only associate with the plant's environmental responses, but also control various aspects of plant growth and development (Gazzarrini and McCourt 2003). This idea was proved to be true when the first plant hormone was identified to be involved in the regulation of many plant processes (Davies 1995).

Among all the phytohormones, gibberellins (GAs) are a large family of tetracyclic diterpenoid that act nearly at all stages of the plant's development, including germination, hypocotyl and stem elongation, leaf expansion, flowering and seed development (Davies 1995). Because of these reasons, it is very important to understand the GA responding mechanism of plant especially crops. In recent years, the identification of GID1 (a GA receptor)

\footnotetext{
* Correspondence: shshen@ibcas.ac.cn

${ }^{2}$ Institute of Botany, Chinese Academy of Sciences, Beijing 100093, China

Full list of author information is available at the end of the article
}

in rice and Arabidopsis brought us a much better understanding about the molecular mechanisms of GA signal transduction (Nakajima et al. 2006; Ueguchi-Tanaka et al. 2005). But the study on the changes of biochemical and physiological processes after sensing the GA signal is still very limited. Functional genomics strategy, such as transcriptomics and proteomics, might be very helpful for us to get a whole idea about what happen in the plant after sensing the signal of GA. Microarray analysis showed that the GA regulated genes have specific ciselements at their upstream regions (Yazaki et al. 2003), and these genes fall into the functional groups of signal transduction, transcription, metabolism, cellular organization, and defense or anti-stress responses (Yang et al. 2004). Using proteomic techniques, it showed that calreticulin might be an important component in the GA signaling pathway that regulates rice seedling leaf-sheath elongation (Komatsu et al. 2006; Shen et al. 2003). They also showed that methylmalonate-semialdehyde dehydrogenase (MMSDH) may play a role in the development of root and elongation of leaf sheath in rice (Tanaka et al. 2005). Because of the limitation on both the 
techniques and genome sequence information, the proteins identified in both of the two studies are very limited. Moreover, they did not show us that biochemical and physiological changes of leaf expansion after sensing GA signal.

Leaf expansion is a complicated regulatory process which is involved in cell division and elongation (Avery 1993), and it has been suggested that the control of cell division and elongation are important factors in the regulation of growth and development (Vernoux et al. 2000). Previous studies have reported that cell division cycle proteins (CDC), cyclins and cyclin-dependent kinases (CDKs) are the important factors which play vital roles in regulating the cell cycle in eukaryotic organisms (Beemster et al. 2003; Inze and De Veylder 2006). The activity of CDKs can be regulated by other proteins through phosphorylation/dephosphorylation, direct binding or proteolysis (King et al. 1996; Morgan 1995). Different CDK-cyclin complexes phosphorylate a plethora of substrates at the key G1-to-S and G2-to-M transition points, triggering the onset of DNA replication and mitosis, respectively. For example, the phosphoprotein CDC34 catalyzes the covalent attachment of ubiquitin which regulates the G1/S transition of the cell cycle (Kaiser et al. 2000); the CDC2/CDC28 is a cyclindependent protein kinase that is required for both $\mathrm{G} 1 / \mathrm{S}$ and $\mathrm{G} 2 / \mathrm{M}$ transitions in yeast (Beach et al. 1982), whereas in higher organisms it is required for G2/M phase transition (Lessard et al. 1999). These studies showed that CDC and CDKs participate in the regulation of cellular cycle directly and thereby regulate cell size and cell number. Hence, we conjecture that CDC or CDKs may be responsible for rice leaf expansion after sensing the signal of GA.

In the present study, to uncover the changes of biochemical and physiological processes in rice leaf, we applied the proteomic analysis of rice seedlings in responding to $\mathrm{GA}_{3}$. Sixty-one proteins have been identified as being up- or down-regulated in response to $\mathrm{GA}_{3}$ treatment. These proteins are involved in signal transduction, cell growth/division, energy metabolism, protein stability, and defense responses, as well as others. These results might help to gain further information about the possible physiological and biochemical changes in rice leaf, hence contribute to the understanding of plant's response to $\mathrm{GA}_{3}$ signals.

\section{Results}

GA content and morphological changes of rice leaf under application of $\mathrm{GA}_{3}$

As mentioned above, GA can act as both the reproductive and vegetative stage of plant development including the expansion of plant leaf. After 8 days treatment with exogenous $\mathrm{GA}_{3}$, the GA content of the leaf showed significant increase (Figure 1A) and the rice seedlings grew at a higher rate than in normal conditions. The growth of the leaf increased dramatically in comparsion with the control (Figure 1B). These are consistent with the observations of rice sheath as previous study has shown (Shen et al. 2003).

\section{Chlorophyll content changes of rice leaf under application of $\mathrm{GA}_{3}$}

Leaf chlorophyll concentration is an important parameter that is frequently measured as an indicator of chloroplast development, photosynthetic capacity, or general plant health. During the application of $\mathrm{GA}_{3}$, chlorophyll content increased slightly for $\mathrm{GA}_{3}$ treatment 2 days, and then declined for $\mathrm{GA}_{3}$ treatment 4, 6, 8 days (Figure 2).

\section{Proteome profile of rice leaf and its changes under application of $\mathrm{GA}_{3}$}

In order to uncover the correlation between the increased growth of rice seedlings and biochemical and physiological changes after application of exogenous $\mathrm{GA}_{3}$, total protein were extracted from the rice leaf and resolved by 2-DE. The experiments (from plants' treatment to 2-DE) were carried out in three replicates for each sample. The leaf proteome was established over the $p I$ range from 3.5 to 8 and molecular mass range from 10 to $100 \mathrm{kDa}$. More than 1000 protein spots could be resolved reproducibly on each gel. Representative gels from the control and treatment plants are shown in Figure 3.

Comparative analysis showed that there were 61 differentially displayed protein spots whose abundance altered at least 1.5 -fold (Student's $t$ test, $\mathrm{p}<0.05$ ) relative to the control. Among these identified protein spots, sixteen were down-regulated (LD1 to LD16), and forty-five were

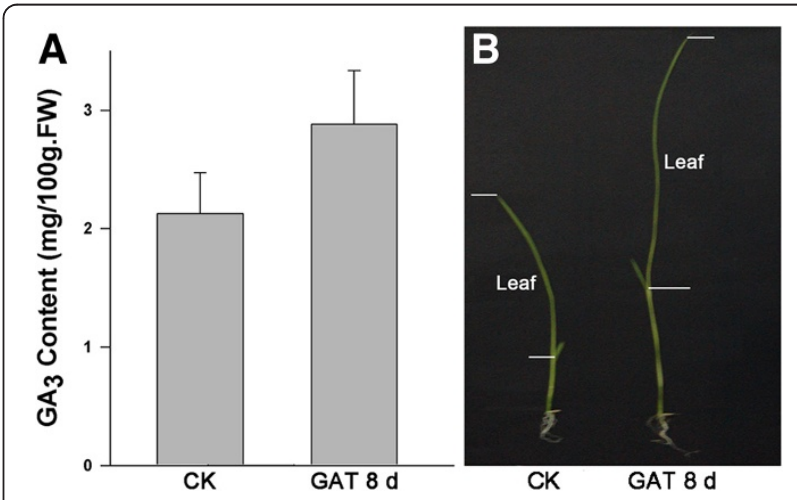

Figure $1 \mathrm{GA}$ content changes in rice leaf and leaf expansion changes in phenotype after application exogenous $G_{3}$. $A$, The $G A$ content of treatment is higher than that of control. Data is representative of three independent experiments and shown as mean + s.e. $\mathbf{B}$, The leaf of treatment is significantly higher than that of control. 


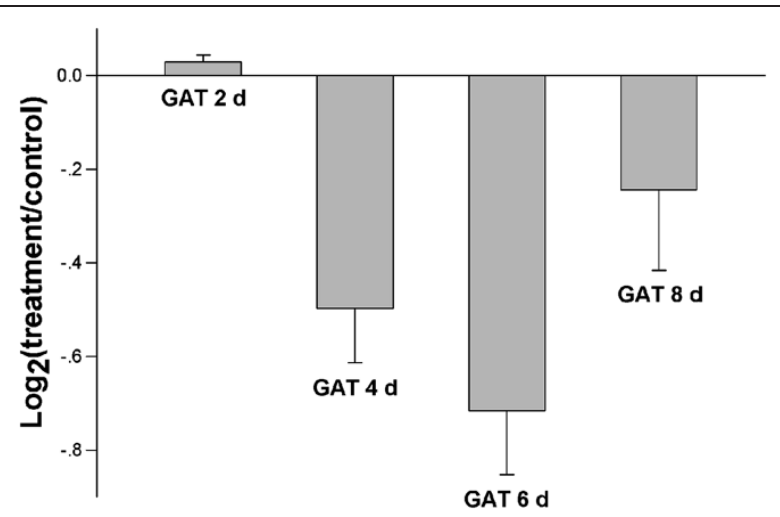

Figure 2 Changes of the chlorophyll content of the rice treated by $\mathrm{GA}_{3}$ for $2,4,6$ and 8 days. Figure plots means \pm SD from three replicate experiments.

up-regulated (LU1 to LU45) (Figure 3). Quantitative changes of these proteins are shown in Figure 4.

The response of exogenous $\mathrm{GA}_{3}$ is a complicated physiological process, in which many biochemical processes might be initiated or inhibited. So, it is reasonable to expect changes in the abundance of the proteins after $\mathrm{GA}_{3}$ treatment. Here, intensities of 61 out 1000 spots have been changed by more than 1.5 -fold and these proteins are worthy of further study.

\section{Protein identification and functional categorization}

To identify the differentially displayed proteins, the protein spots were excised from the 2D gels. After trypsin digestion, the peptides were extracted from the gel and analyzed by MALDI-TOF MS. Using the criteria described in Methods, we identified confidently 61 GAresponsive protein spots (Table 1). We observed some differences between the experimental and theoretical MWs and pIs of the proteins we identified. This may be due to post-translational modification of the proteins.

The identified proteins could be sorted into 8 categories (Table 1, Figure 5) according to their function as described by the EU Arabidopsis Genome Project (Bevan et al. 1998). These functional classes included energy, metabolism, defense, protein stability, cell growth/ division, signal transduction, and transposons (Table 1, Figure 5). Among them, proteins of the energy and metabolism groups accounted for more than $65.7 \%$ of the total number identified.

\section{Proteins down-regulated by $\mathrm{GA}_{3}$ treatment}

Sixteen proteins were down-regulated following application of exogenous $\mathrm{GA}_{3}$. Seven of them were identified as a subunit of ribulose bisphosphate carboxylase/oxygenase (spots LD2, LD5, LD7, LD13, LD14, LD15 and LD16). They catalyze the first step in net photosynthetic $\mathrm{CO}_{2}$ assimilation and photorespiration carbon oxidation.
Carbonic anhydrase (spot LD10), which plays a role in converting bicarbonate ions back to carbon dioxide for photosynthesis, is also identified. In addition, proteins related to transposons (spots LD9 and LD12) were also down-regulated. Our results suggest that the photosynthesis might be inhibited by application of exogenous $\mathrm{GA}_{3}$. This may lead to reduced energy of the cells.

\section{Proteins up-regulated by $\mathrm{GA}_{3}$ treatment}

Forty-five proteins were up-regulated in response to application of exogenous $\mathrm{GA}_{3}$. Among them, more than 53.3\% of the proteins belonged to four functional groups: energy, metabolism, protein stability and defense.

The proteins involved with energy and metabolism proteins were mainly linked to glycolysis, citric acid cycle, pentose phosphste pathway and polysaccharide synthesis, including glyceraldehyde-3-phosphate dehydrogenase (spots LU28 and LU29), phosphoglycerate mutase (spot LU9), UDP-glucuronic acid decarboxylase (spot LU27), UDP-glucose pyrophosphorylase (spot LU23) and ATPase alpha subunit (spot LU20). This suggests that energy metabolism is activated by application of exogenous $\mathrm{GA}_{3}$.

The proteins involved in defense and protein stability were the third most abundant category of up-regulated proteins. There were DnaK-type molecular chaperone hsp70 (spot LU8), disulfide isomerase (spots LU14, LU15), chaperonin 21 (spot LU41) and catalase (spots LU16, LU17, LU18). An important role of molecular chaperones (spots LU8 and LU41) is stabilizing protein conformation by preventing the aggregation of denatured or incompletely folded proteins and by promoting the re-naturation of aggregated proteins (Boston et al. 1996). Protein disulfide isomerase (spots LU14, LU15), an enzyme located in the endoplasmic reticulum, catalyzes the folding of many disulfide-bonded proteins (Freedman, 1984). Catalase (spots LU16, LU17, LU18) is a key antioxidant enzyme in the bodie's defense against oxidative stress. It converts the reactive oxygen species hydrogen peroxide to water and oxygen and thereby mitigates the toxic effects of hydrogen peroxide. Their upregulation suggests that defense is also enhanced as a response to application of exogenous $\mathrm{GA}_{3}$ in this plant.

Proteins associated with signal transduction (receptor protein kinase-related protein; spot LU19; Figure 2) and cell growth/division (cell division cycle protein 48, CDC48; spots LU2 and LU3) were also up-regulated. CDC48 is a highly abundant type II AAA-ATPase associated with two copies of the highly conserved ATPase domain, with each containing the consensus Walker A and B motifs which are responsible for ATP binding and hydrolysis, respectively (Buchberger 2010). Upon ATP binding and hydrolysis, CDC 48 undergo conformational changes, which could generate a pulling force to 


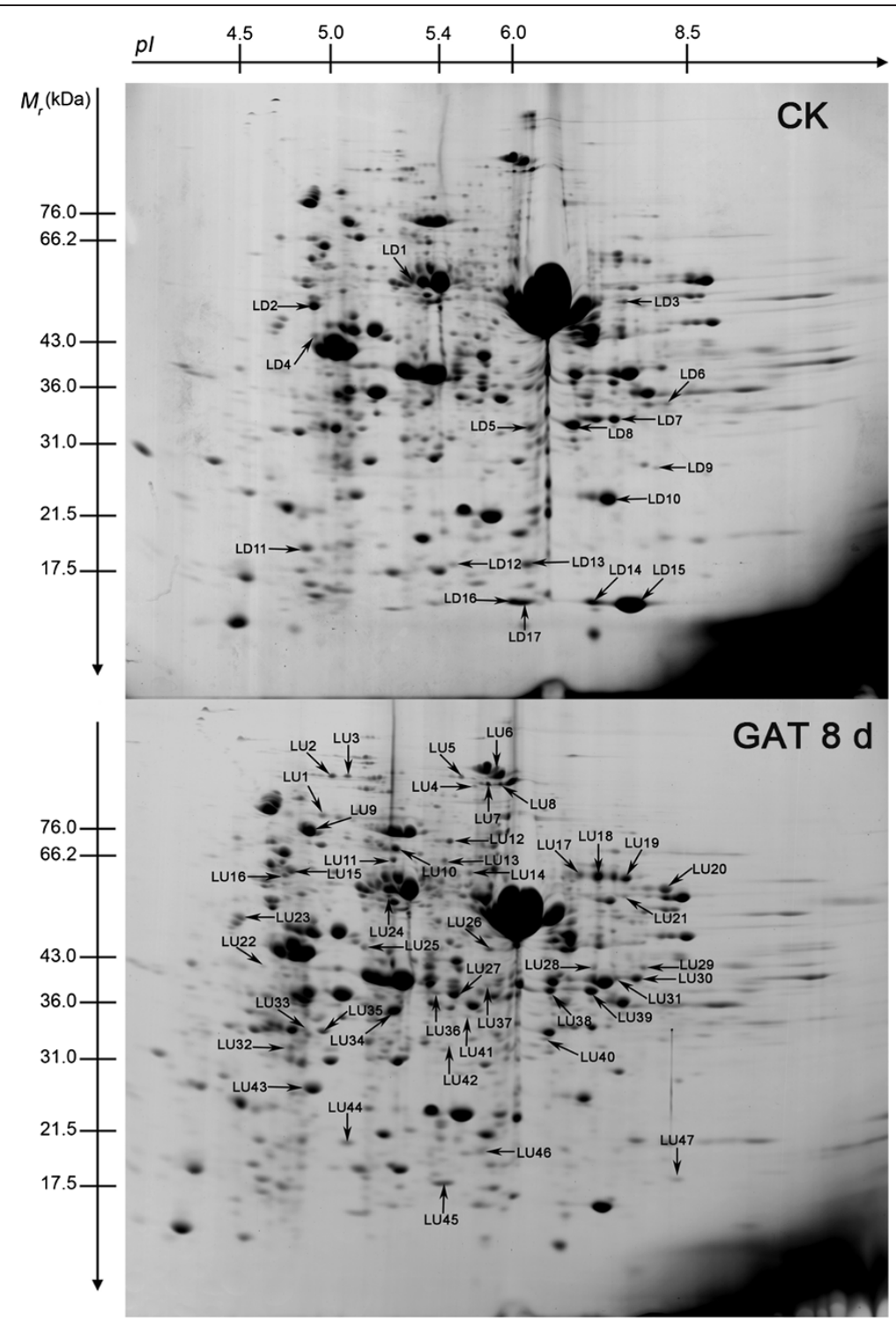

Figure 3 Representative 2-DE gels of rice leaf proteins after application exogenous $\mathrm{GA}_{3}$. Upper image: Control; lower image: $\mathrm{GA}_{3}$ treatment 8 days. GA-responsive proteins are indicated as follows: LD, down-regulated protein; LU, up-regulated protein. Gels are coommassie stained.

disassemble a protein complex such as mitotic spindle (Cheeseman and Desai 2004).

\section{Quantitative real-time PCR analysis of GA-responsive genes in P. patens}

To correlate protein level with the corresponding mRNA level of the GA-responsive genes, we performed quantitative real-time PCR. We analyzed the expression of 15 genes which were identified as GA-responsive genes. Except for a few genes, mRNA levels of most genes changed in parallel with protein levels (Figure 6). The parallel and independent relations that exist between mRNA and protein levels among GA-responsive genes imply the existence of a fairly complex regulatory network.

\section{Discussion}

Because of its positive effects on plants, GAs have been regarded as a major plant hormone for controlling growth and development. It is well established that GAs are responsible for triggering stem or internodal elongation. In rice seedlings, the basal part of the leaf sheath contains root primodia and meristem cells, which undergo active cell division and development (Yang et al. 2005). Proteomic studies have focused on the mechanism of rice leaf sheath elongation following $\mathrm{GA}_{3}$ treatment. They have been shown that calreticulin is an 

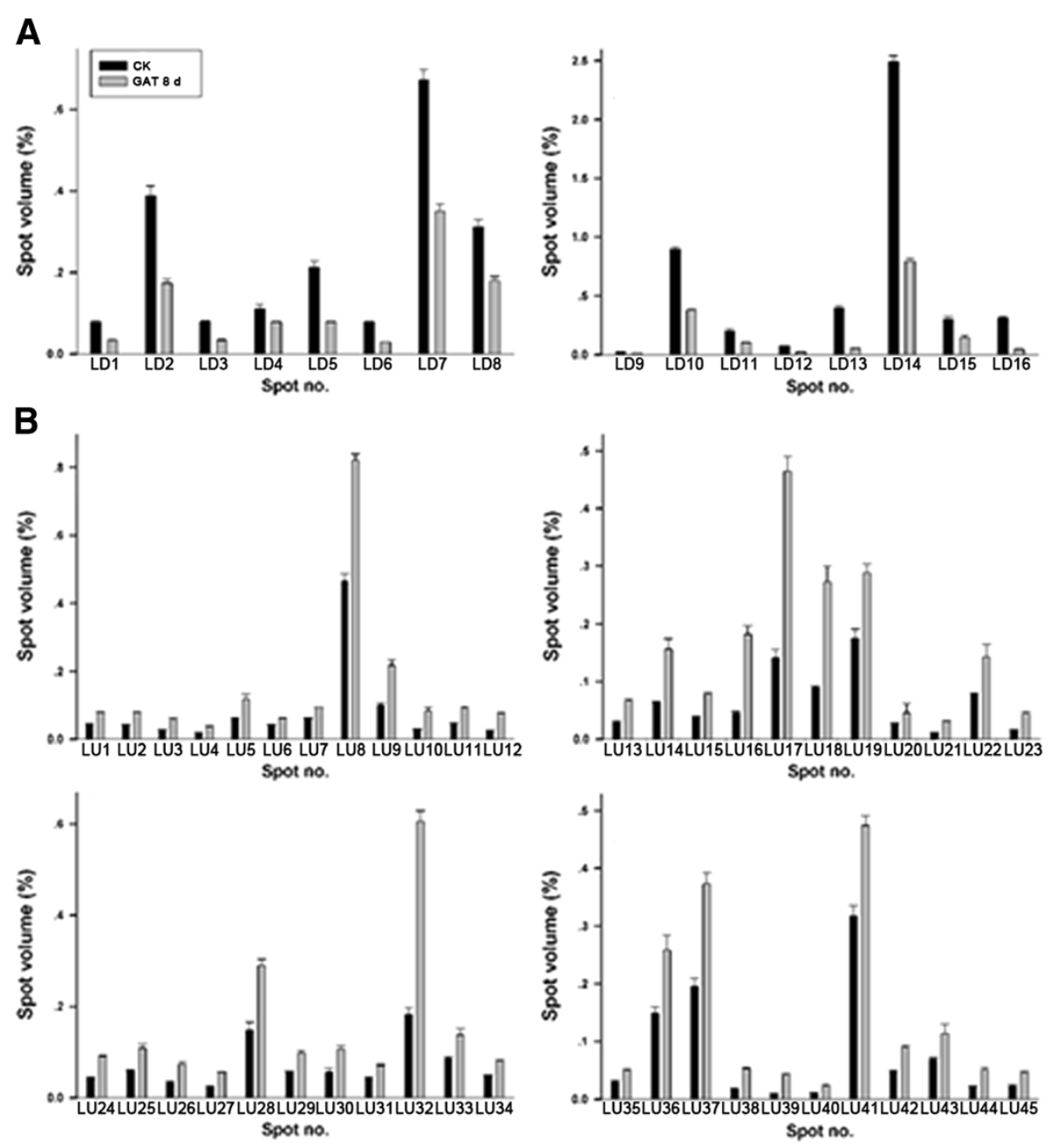

Figure 4 Expression changes of the differentially displayed proteins. A, Proteins down-regulated in response to $\mathrm{GA}_{3}$ as identified in Figure 2; $\mathbf{B}$, Proteins up-regulated in response to $\mathrm{GA}_{3}$ as identified in Figure 2. The protein abundance is presented as the percentage of the total spot volume associated with each identified spot. Data is representative of three independent experiments and shown as mean + s.e.

important component in regulating rice seedling leaf sheath elongation. Further, the $\mathrm{GA}_{3}$ can induce the synthesis of many proteins in rice leaf sheath, including chaperones, metabolic enzymes, and detoxification enzymes (Komatsu et al. 2006; Shen et al. 2003; Tanaka et al. 2004). However, the study on the leaf expansion after sensing the GA signal is still very limited. In this work, the $\mathrm{GA}_{3}$-induced changes in the proteome of rice leaf were analyzed after treatment with GAs for 8 days. This study can help to reveal the mechanism of leaf expansion in response to GAs.

\section{Signal transduction and cell growth/division}

Studies have shown that plant cells sense signal at the plasma membrane and then initiate signal transduction to regulate the expression of a series of relevant genes. Receptor protein kinases are plasma membrane-bound and play an important role in the perception and transmittance of external signals such as ABA, dehydration, high salt and cold treatments (Hong et al. 1997). In our study, receptor protein kinase-related protein-like (spot LU19) was up-regulated, implying that it was responsible for GA signal transduction and in turn aroused a series of physiological and biochemical changes. Plant morphological development requires the coordination of cell division, expansion, and differentiation (Beemster et al. 2003; Fleming 2006; Meijer and Murray 2001). It is known that GA can stimulate leaf expansion by an increase in cell length and cell number (Yang et al. 1996), with the promotion in cell extension being largely conferred by an enhanced wall extensibility (Cosgrove and Sovonick-Dunford 1989). Previous studies have been reported that cell division cycle protein 48 (CDC48; spots LU2 and LU3) may be directly involved in cell expansion, cell division and cell proliferation (Park et al. 2008; Rancour et al. 2004). Up-regulation of 
Table 1 Identification of GA-responsive proteins in rice leaf

\begin{tabular}{|c|c|c|c|c|c|c|c|c|}
\hline $\begin{array}{l}\text { Protein } \\
\text { ID }\end{array}$ & Accession no. & $\begin{array}{l}\text { Theor Mr } \\
\text { (kD)/pl }\end{array}$ & $\operatorname{Exp} .(\mathrm{kD}) / \mathrm{pl}$ & Description & $\begin{array}{l}\text { Matched/searched } \\
\text { peptides }\end{array}$ & Score & $\begin{array}{l}\text { Sequence } \\
\text { coverage (\%) }\end{array}$ & Metabolic group \\
\hline LD1 & AAA84588 & $54.0 / 5.30$ & $57.6 / 5.29$ & AtpB gene product & $14 / 46$ & 139 & 51 & Unknown \\
\hline LD2 & BAC78572 & $51.8 / 5.43$ & $51.4 / 4.91$ & $\begin{array}{l}\text { Ribulose-bisphosphate carboxylase } \\
\text { activase large isoform precursor protein }\end{array}$ & $13 / 28$ & 142 & 37 & Energy \\
\hline LD3 & BAD20105 & $30.3 / 11.81$ & $52.5 / 7.65$ & Hypothetical protein & $7 / 41$ & 64 & 37 & Unknown \\
\hline LD4 & EAZ34180 & $8.02 / 6.84$ & $45.3 / 4.92$ & Hypothetical protein OsJ_017663 & $4 / 14$ & 71 & 54 & Unknown \\
\hline LD5 & CAG34174 & $53.3 / 6.23$ & $31.3 / 6.26$ & Ribulose bisphosphate carboxylase large chain & $11 / 77$ & 66 & 20 & Energy \\
\hline LD6 & BAD38069 & 22.3/9.97 & $34.8 / 8.24$ & Hypothetical protein & $10 / 71$ & 73 & 54 & Unknown \\
\hline LD7 & CAG34174 & $53.3 / 6.23$ & $32.3 / 7.46$ & Ribulose bisphosphate carboxylase large chain & $9 / 35$ & 79 & 21 & Energy \\
\hline LD8 & BAD35346 & $13.7 / 10.25$ & $31.8 / 6.89$ & Hypothetical protein & $5 / 29$ & 62 & 52 & Unknown \\
\hline LD9 & ABA99483 & $120.3 / 8.37$ & 26.8/8.07 & Retrotransposon protein, putative, unclassified & $10 / 28$ & 65 & 13 & Transposons \\
\hline LD10 & BAA31953 & $29.5 / 8.41$ & 23.7/7.37 & Carbonic anhydrase & $6 / 34$ & 64 & 30 & Energy \\
\hline LD11 & O22386 & 18.6/5.36 & 19.3/4.86 & $50 S$ ribosomal protein L12, chloroplast precursor (CL12) & $5 / 26$ & 66 & 40 & Protein stability \\
\hline LD12 & ABA99483 & $120.3 / 8.37$ & 18.0/5.53 & Retrotransposon protein, putative, unclassified & $10 / 28$ & 65 & 13 & Transposons \\
\hline LD13 & AAR19268 & 19.8/9.03 & $15.6 / 7.19$ & Ribulose-1,5-bisphosphate carboxylase/oxygenase small subunit & $12 / 41$ & 149 & 62 & Energy \\
\hline LD14 & AAR19268 & 19.8/9.03 & $15.2 / 7.69$ & Ribulose-1,5-bisphosphate carboxylase/oxygenase small subunit & $11 / 28$ & 145 & 57 & Energy \\
\hline LD15 & AAR19268 & 19.8/9.03 & 15.5/5.98 & Ribulose-1,5-bisphosphate carboxylase/oxygenase small subunit & $13 / 43$ & 166 & 70 & Energy \\
\hline LD16 & AAR19268 & 19.8/9.03 & $15.5 / 6.16$ & Ribulose-1,5-bisphosphate carboxylase/oxygenase small subunit & $11 / 26$ & 164 & 57 & Energy \\
\hline LU1 & AAB63469 & $73.7 / 5.30$ & $79.2 / 4.91$ & Endosperm lumenal binding protein & $7 / 10$ & 90 & 15 & Unknown \\
\hline LU2 & AAP53974 & $90.5 / 5.09$ & $92.3 / 5.02$ & Cell division cycle protein 48 , putative, expressed & $16 / 40$ & 118 & 22 & Cell growth/division \\
\hline LU3 & AAP53974 & $90.5 / 5.09$ & $92.8 / 5.07$ & Cell division cycle protein 48 , putative, expressed & $20 / 47$ & 158 & 27 & Cell growth/division \\
\hline LU4 & ABB47613 & $92.1 / 6.28$ & $89.6 / 5.70$ & Prolyl oligopeptidase family, putative & $15 / 68$ & 83 & 28 & Unknown \\
\hline LU5 & BAD35509 & $112.4 / 6.35$ & $95.1 / 5.89$ & Putative glycine dehydrogenase & $12 / 22$ & 124 & 20 & Metabolism \\
\hline LU6 & BAC75578 & $15.5 / 10.82$ & $89.6 / 5.82$ & Hypothetical protein & $5 / 26$ & 65 & 51 & Unknown \\
\hline LU7 & NP_001052057 & $95.0 / 5.85$ & $89.6 / 5.92$ & Os04g0118400 & $11 / 26$ & 106 & 20 & Unknown \\
\hline LU8 & AAX95352 & $71.5 / 5.10$ & $74.1 / 4.89$ & DnaK-type molecular chaperone hsp70 - rice (fragment) & $15 / 45$ & 96 & 23 & Protein stability \\
\hline LU9 & BAD82294 & $60.9 / 5.42$ & $68.9 / 5.24$ & Putative phosphoglycerate mutase & $14 / 43$ & 105 & 30 & Energy \\
\hline LU10 & AAR01748 & $42.2 / 6.10$ & $65.8 / 5.24$ & Methylenetetrahydrofolate reductase, 3-partial & $7 / 23$ & 67 & 24 & Metabolism \\
\hline LU11 & CAE05155 & $75.4 / 5.83$ & $65.8 / 5.48$ & OSJNBa0039C07.11 & $12 / 21$ & 129 & 22 & Unknown \\
\hline LU12 & NP_001043066 & $62.9 / 5.68$ & $62.3 / 5.44$ & Os01g0372700 & $15 / 39$ & 126 & 26 & Unknown \\
\hline LU13 & NP_001049057 & $60.6 / 7.25$ & $62.6 / 5.66$ & Os03g0163300 & $10 / 54$ & 72 & 25 & Unknown \\
\hline LU14 & AAX85991 & $57.1 / 4.95$ & $62.8 / 4.79$ & Protein disulfide isomerase & $15 / 72$ & 98 & 34 & Protein stability \\
\hline LU15 & AAX85991 & $57.1 / 4.95$ & $61.7 / 4.75$ & Protein disulfide isomerase & $9 / 34$ & 63 & 20 & Protein stability \\
\hline
\end{tabular}


Table 1 Identification of GA-responsive proteins in rice leaf (Continued)

\begin{tabular}{|c|c|c|c|c|c|c|c|c|}
\hline LU16 & CSRZ & $57.1 / 6.75$ & $62.3 / 6.99$ & Catalase (EC 1.11.1.6) catA & $7 / 25$ & 69 & 23 & Defence \\
\hline LU17 & CSRZ & $57.1 / 6.75$ & $61.7 / 7.25$ & Catalase (EC 1.11.1.6) catA & $19 / 53$ & 176 & 51 & Defence \\
\hline LU18 & CSRZ & $57.1 / 6.75$ & $61.4 / 7.65$ & Catalase (EC 1.11.1.6) catA & $12 / 38$ & 92 & 27 & Defence \\
\hline LU19 & BAC84709 & $60.6 / 7.19$ & $58.2 / 8.20$ & Receptor protein kinase-related protein-like & $6 / 22$ & 73 & 15 & Signal transduction \\
\hline LU20 & AAM12499 & $55.2 / 5.95$ & $57.0 / 7.63$ & ATPase alpha subunit & $10 / 42$ & 120 & 30 & Energy \\
\hline LU21 & BAD53795 & $46.7 / 5.81$ & $42.8 / 4.64$ & Putative aminolevulinate dehydratase & $11 / 70$ & 74 & 35 & Metabolism \\
\hline LU22 & ABF99934 & $37.3 / 4.64$ & $52.1 / 4.51$ & Ankyrin repeat domain protein 2, putative, expressed & $11 / 35$ & 132 & 45 & Metabolism \\
\hline LU23 & ABD57308 & $51.8 / 5.43$ & $56.8 / 5.22$ & UDP-glucose pyrophosphorylase & $11 / 59$ & 77 & 35 & Energy \\
\hline LU24 & NP_001047463 & $45.4 / 5.98$ & $46.5 / 5.13$ & Os02g0621700 & $16 / 56$ & 147 & 48 & Unknown \\
\hline LU25 & AAO23563 & $46.0 / 5.90$ & $45.8 / 5.82$ & Aspartate aminotransferase & $21 / 58$ & 213 & 59 & Metabolism \\
\hline LU26 & EAZ41273 & $42.0 / 8.46$ & $42.6 / 7.18$ & Hypothetical protein OsJ_024756 & $7 / 37$ & 65 & 24 & Unknown \\
\hline LU27 & BAB84334 & $39.5 / 7.16$ & $42.6 / 7.89$ & UDP-glucuronic acid decarboxylase & $11 / 57$ & 90 & 44 & Energy \\
\hline LU28 & AAA82047 & $36.6 / 6.61$ & $40.7 / 7.79$ & Glyceraldehyde-3-phosphate dehydrogenase & $7 / 15$ & 100 & 33 & Energy \\
\hline LU29 & AAA82047 & $36.6 / 6.61$ & $40.9 / 7.49$ & Glyceraldehyde-3-phosphate dehydrogenase & $7 / 21$ & 80 & 27 & Energy \\
\hline LU30 & AAX96859 & $51.6 / 9.06$ & $30.7 / 4.78$ & Acetolactate synthase, small subunit, putative & $9 / 24$ & 62 & 16 & Metabolism \\
\hline LU31 & BAD35207 & $34.5 / 5.61$ & $33.2 / 4.86$ & Putative PrMC3 & $14 / 41$ & 157 & 46 & Unknown \\
\hline LU32 & BAB71741 & $32.9 / 5.51$ & $35.8 / 5.24$ & Glyoxalase I & $4 / 16$ & 75 & 27 & Energy \\
\hline LU33 & NP_001060741 & $27.2 / 5.21$ & $32.8 / 4.97$ & Os07g0694700 & $9 / 20$ & 135 & 58 & Unknown \\
\hline LU34 & AAL61542 & $33.5 / 5.69$ & $38.5 / 5.39$ & Isoflavone reductase-like protein & $7 / 25$ & 85 & 42 & Metabolism \\
\hline LU35 & BAD08085 & $39.9 / 6.37$ & $39.5 / 5.81$ & Putative ornithine carbamoyltransferase & $8 / 35$ & 75 & 34 & Metabolism \\
\hline LU36 & NP_001053139 & $36.9 / 6.34$ & $38.7 / 6.57$ & Os04g0486600 & $8 / 20$ & 108 & 39 & Unknown \\
\hline LU37 & NP_001053139 & $36.9 / 6.34$ & $38.7 / 7.14$ & Os04g0486600 & $12 / 56$ & 104 & 45 & Unknown \\
\hline LU38 & NP_001054439 & $31.4 / 9.13$ & $31.9 / 6.52$ & Os05g0110300 & $7 / 34$ & 67 & 22 & Unknown \\
\hline LU39 & BAD25718 & $28.8 / 5.46$ & $35.1 / 5.65$ & Putative porphobilinogen deaminase & $7 / 48$ & 64 & 35 & Metabolism \\
\hline LU40 & ABA93708 & $85.5 / 8.06$ & $31.1 / 5.48$ & NB-ARC domain, putative & $11 / 31$ & 64 & 16 & Unknown \\
\hline LU41 & BAD36628 & 23.2/5.72 & 25.9/4.91 & Putative chaperonin 21 precursor & $14 / 42$ & 181 & 74 & Protein stability \\
\hline LU42 & BAB70686 & $79.6 / 5.37$ & 20.9/5.07 & Ryptochrome 1a & $6 / 26$ & 65 & 10 & Unknown \\
\hline LU43 & BAD32104 & 24.8/11.92 & $17.8 / 5.44$ & Splicing coactivator subunit-like protein & $6 / 28$ & 65 & 28 & Metabolism \\
\hline LU44 & NP_001042680 & $21.0 / 7.77$ & $20.2 / 5.77$ & Os01g0266600 & $6 / 31$ & 74 & 54 & Unknown \\
\hline LU45 & EAZ35500.1 & 21.6/8.38 & 18.1/8.36 & Hypothetical protein OsJ_018983 & $5 / 15$ & 70 & 24 & Unknown \\
\hline
\end{tabular}


CDC48 by application exogenous $\mathrm{GA}_{3}$ indicates that CDC48 may be responsible for rice leaf expansion.

\section{Photosynthesis inhibition}

A major effect of GAs on plant seedlings has been reported as producing increased rates of growth in size and weight. Such growth might be due to an increased rate of photosynthesis. However, the study of photosynthesis in several species indicated that GA did not enhance the rate of $\mathrm{CO}_{2}$ fixation per unit of leaf tissue (Haber and Tolbert 1957), and that photosynthesis was unaffected during leaf expansion (Haag-Kerwer et al. 1999). In our study, 7 out of 16 down-regulated spots in the group belonging to photosynthetic enzymes were identified (spots LD2, LD5, LD7, LD10, LD13, LD14, LD15 and LD16). During the application of $\mathrm{GA}_{3}$, chlorophyll content decreased for $\mathrm{GA}_{3}$ treatment 4, 6, 8 days (Figure 2). These suggest that photosynthesis may be inhibited following the application of exogenous $\mathrm{GA}_{3}$. This is consistent to several studies on plant photosynthesis in response to GA (Dijkstra et al. 1990; Thetford et al. 1995).

\section{Catabolic metabolism enhanced}

In contrast to the apparent decrease of photosynthesis, the catabolic metabolism seems to be enhanced after application of exogenous $\mathrm{GA}_{3}$, or at least poised for enhancement, as seen from the increase in several energy related proteins (spots LU28, 29, LU9, LU27, LU23, and LU20). These enzymes are involved in energy metabolism pathway such as glycolysis, citric acid cycle, and pentose phosphate pathway and polysaccharide synthesis. Glycolysis and citric acid cycle are the main pathway for organisms to produce energy; the pentose phosphate pathway meets the need of all organisms for a source of $\mathrm{NADPH}$ to use in reductive biosynthesis; polysaccharide can store energy for organisms growth and development. These results may reflect that exogenous $\mathrm{GA}_{3}$ can accelerate energy in more than one way: it not only enhance energy directly by up-regulating ATPase alpha subunit (spot LU20), but also affects catabolic metabolism pathway. The same results have been reported in previous studies (Fu et al. 2005; Tanaka et al. 2004; Yang et al. 2004).

\section{Protein stability assurance}

Protein stability related proteins were also identified in response to exogneous $\mathrm{GA}_{3}$. Molecular chaperones (spots LU8, LU41) are such proteins that can assist in de novo protein folding, stabilize proteins under stress conditions and maintain polypeptide chain components in a loosely folded state for translocation across organellar membranes (Hartl, 1996; Wang et al., 2004). Our data demonstrated that the expression of molecular chaperone proteins was enhanced in response to exogenous $\mathrm{GA}_{3}$, suggesting that $\mathrm{GA}_{3}$ increased a potential capacity of protein stability and cellular stress response. A pair of protein stability related proteins up-regulated by application exogenous $\mathrm{GA}_{3}$ are protein disulfide isomerase (PDI; spots LU14 and LU15). It also can assist the protein refolding to its active state by suppressing aggregation, which is closely similar to the action of chaperones (Cai et al. 1994). Together, it seems that plants have evolved protective mechanisms to adjust to cell expansion.

\section{Accumulation of defense proteins}

Along with above-mentioned components of energy metabolism and protein stability, exogenous $\mathrm{GA}_{3}$ also up-regulated several proteins associated with defense against stress. Catalase (spots LU16, LU17 and LU18) is such an antioxidant enzyme from many species known to rapidly convert hydrogen peroxide into oxygen and water. In this study, the possible explanations for up-

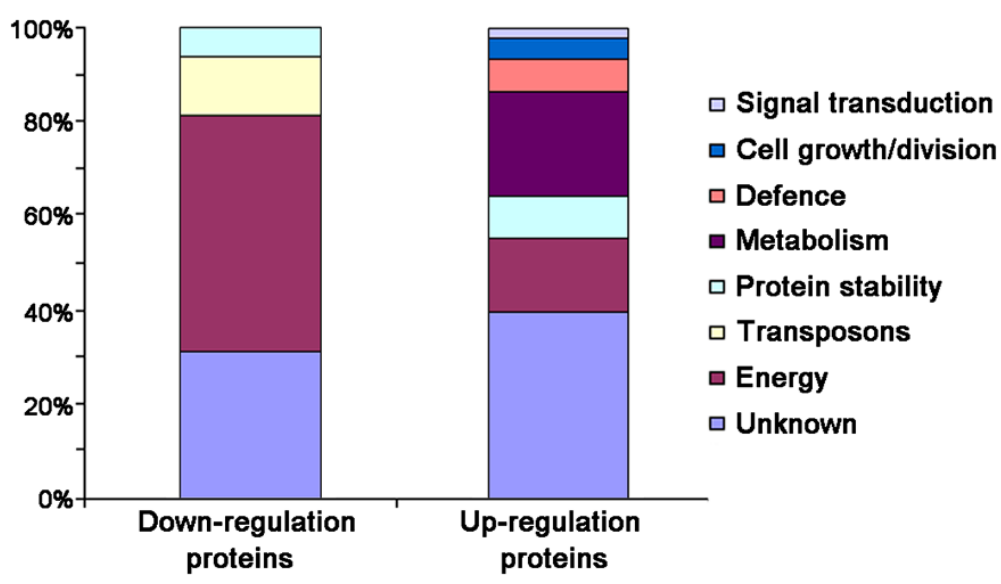

Figure 5 Functional categorization of the GA-responsive proteins. Seven groups were represented by up-regulated proteins and only four groups by down-regulated proteins. 


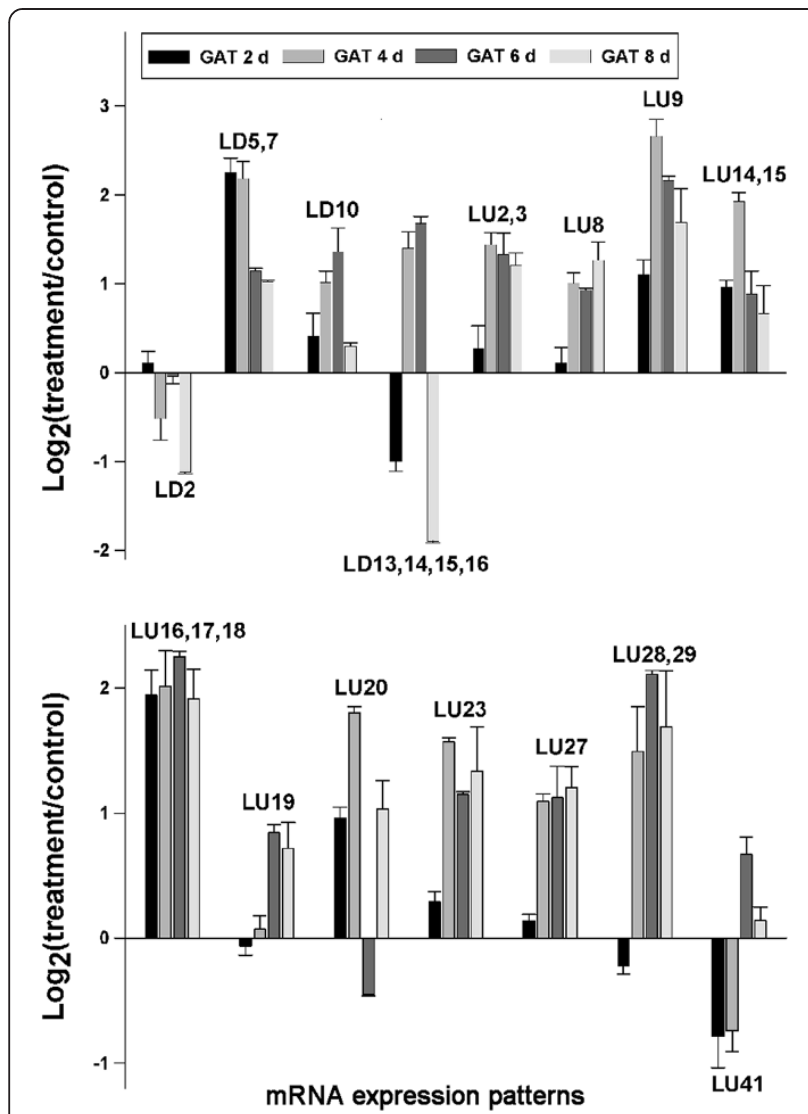

Figure 6 mRNA expression patterns. The $\log _{2}$ values were plotted as the relative expression of the rice treated by $\mathrm{GA}_{3}$ for $2,4,6$ and 8 days.

regulation of catalase may be as follows. First, the reduction of photosynthesis and enhancement of respiration will increase the formation of reactive oxygen species and hence increase the accumulation and activity of catalase that detoxifies hydrogen peroxide (Pellinen et al. 2002). Second, leaf expansion is corrected with cell wall loosening which is generally assumed to involve the scission of plant cell wall polysaccharides (Fry 1998). Along with the scission of cell wall polysaccharides, the hydroxyl radicals $(\cdot \mathrm{OH})$ which is produced by the reaction of hydrogen peroxide $\left(\mathrm{H}_{2} \mathrm{O}_{2}\right)$ with oxygen $\left(\mathrm{O}_{2}\right)$ have been shown to increase (Fry 1998). Our study showed that up-regulation of the catalase may be responsible for scavenging $\mathrm{H}_{2} \mathrm{O}_{2}$ generated by cell wall-loosening during leaf expansion. Therefore, it is not surprising that the expression of enzymes related to anti-oxidation was enhanced significantly in response to application exogenous $\mathrm{GA}_{3}$. Previous study has shown the same result in rice leaf sheath (Komatsu et al. 2006).

\section{Conclusions}

This study presents a comprehensive analysis of rice leaf proteome in response to exogenous $\mathrm{GA}_{3}$ (Figure 7). Upon the application of exogenous $\mathrm{GA}_{3}$, rice leaf cells can sense $\mathrm{GA}_{3}$ and transmit a signal, which in turn, activates cell growth/division, energy metabolism, protein stability and defensive genes expression. These results should serve as useful starting points to develop a complete understanding of how the plant cell responds to $\mathrm{GA}_{3}$ signal.

\section{Methods}

\section{Plant material and $\mathrm{GA}_{3}$ treatments}

Rice (Oryza sativa L. spp. Japonica var. Nipponbare) seeds were allowed to germinate in distilled water for 48 $\mathrm{h}$ at $26^{\circ} \mathrm{C}$. The germinated seeds were sown in beakers containing complete kimura $\mathrm{B}$ nutrient solution. For $\mathrm{GA}_{3}$ treatments, $5 \mu \mathrm{M} \mathrm{GA}_{3}$ was added into the nutrient solution. Seedlings were cultured under white light (150 $\mu \mathrm{mol}$ photons $/ \mathrm{m}^{2} \mathrm{~s} ; 14 \mathrm{~h}$ light $/ 10 \mathrm{~h}$ dark) at $26^{\circ} \mathrm{C}$ in a growth chamber. After 8 days, the second leaves were cut down for protein extraction. For quantitative realtime PCR and chlorophyll measure, $5 \mu \mathrm{M} \mathrm{GA}_{3}$ was added to the nutrient solution when seedlings growth for $0,2,4,6$ days. After 8 days, the second leaves were cut down for RNA and chlorophyll extraction.

\section{$\mathrm{GA}_{3}$ extraction and measure}

The $\mathrm{GA}_{3}$ was extracted from rice leaf according to Kelen et al., (2004) with some modification. In brief, a half gram of leaf was ground into fine powder in liquid nitrogen. The powder was mixed with $30 \mathrm{ml}$ ice-cold methanol for $1 \mathrm{~h}$ and then put into fridge $\left(4^{\circ} \mathrm{C}\right)$ overnight. The mixture was strained through filter paper. The $\mathrm{GA}_{3}$ was reextracted from the residue as mentioned above. The liquid phase (methanol containing hormones of $\mathrm{GA}_{3}$ ) was merged and evaporated to $10 \mathrm{ml}$ under vacuum. All the samples were filtered through $0.45 \mu \mathrm{m}$ membrane (Millipore) using a filtration syringe system for analysis.

The content of $\mathrm{GA}_{3}$ was determined using highpressure liquid chromatography (HPLC). Liquid chromatography was performed using Waters LC (Model 244) equipped with reversed phase column Diamosil C18 $(250 \mathrm{~mm} \times 4.0 \mathrm{~mm})$. The mobile phase was methanolacetonitrile-water $(20 / 15 / 65 ; \mathrm{v} / \mathrm{v})$, and $\mathrm{pH}$ was adjusted to 3.0 using $0.1 \mathrm{M} \mathrm{H}_{3} \mathrm{PO}_{4}$. The injection volume was $10 \mu \mathrm{l}$, the column temperature was set to $30^{\circ} \mathrm{C}$, and the flow rate was $0.8 \mathrm{ml} / \mathrm{min}$. The signal of the compound was monitored at $254 \mathrm{~nm}$ for $\mathrm{GA}_{3}$. The standard solution of $\mathrm{GA}_{3}$ was made in the mobile phase and chromatographed separately to identify retention time of $\mathrm{GA}_{3}$. The experiment was carried out in three repeats and the results were exported to SPSS Version 13.0 for statistical analysis using t- test $(\mathrm{P}<0.05)$.

\section{Determination of chlorophyll content}

To determine chlorophyll content, freshly harvested samples were extracted in a one to one mixture of acetone and 


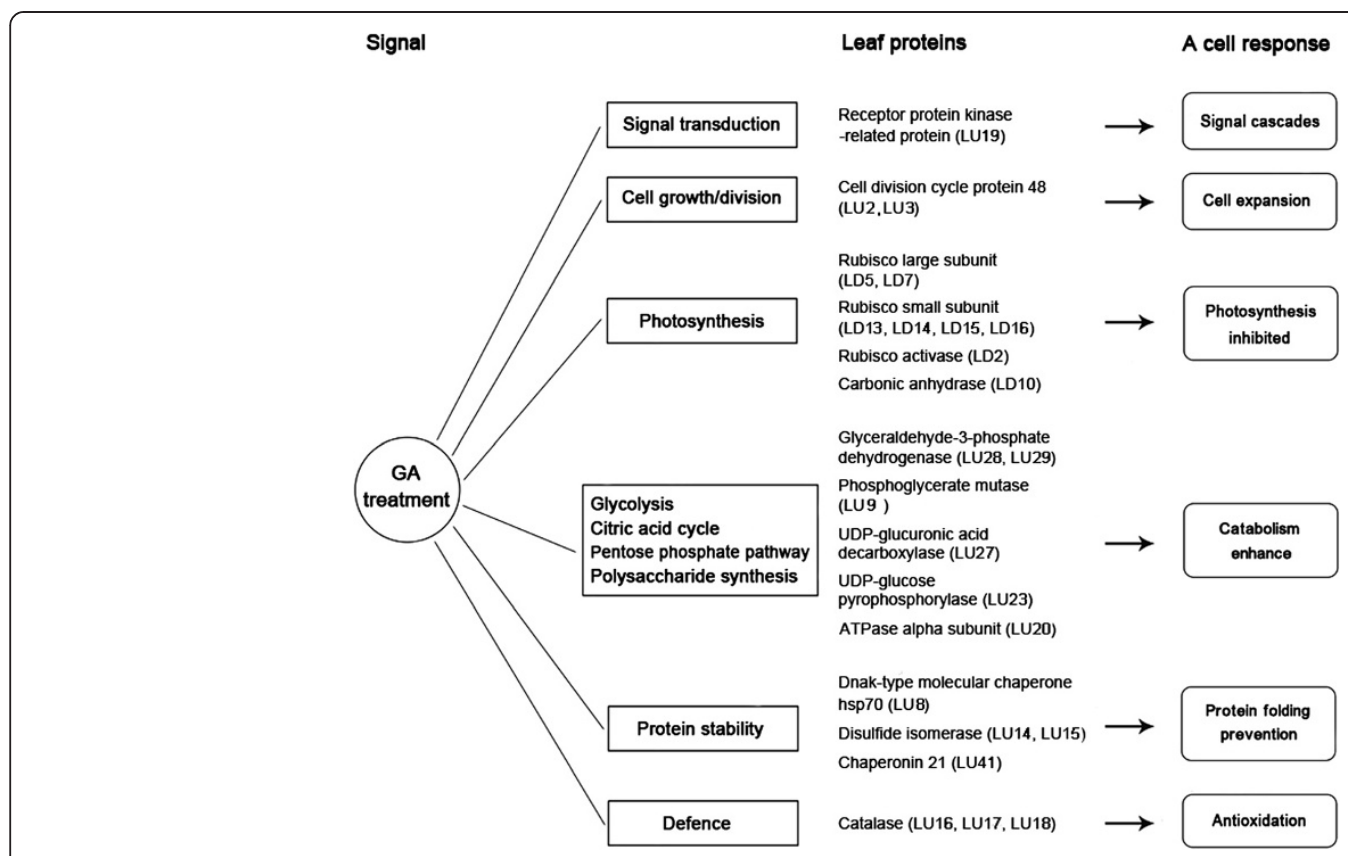

Figure 7 Cell responses corresponding to identified proteins under the treatment by $\mathrm{GA}_{3}$.

ethanol, as described by Chen (1984), and the absorbance of the extract samples were measured at $652 \mathrm{~nm}$ with a spectrophotometer (GE Healthcare BIO-Science). Chlorophyll content was calculated based on Arnon (1949).

\section{Protein extraction and 2-DE}

Proteins were extracted under a denaturing condition according to the procedure (phenol extraction procedure) described by Wang et al. (2009a) with minor modification. One $g$ of leaf was ground into fine powder in liquid nitrogen and homogenized on ice with $2 \mathrm{ml}$ ice-cold extraction buffer (250 mM sucrose, $20 \mathrm{mM}$ Tris $-\mathrm{HCl}$ $\mathrm{pH}$ 7.5, $10 \mathrm{mM}$ EDTA, $1 \mathrm{mM}$ PMSF, and $1 \mathrm{mM}$ DTT). Then an equal volume of ice-cold Tris- $\mathrm{HCl} \mathrm{pH} \mathrm{7.5-}$ saturated phenol was added, and the mixture was rehomogenized on ice. After centrifugation (20 min, $\left.15,000 \mathrm{~g}, 4^{\circ} \mathrm{C}\right)$, the phenol phase was collected. Proteins were precipitated from the final phenol phase with three volumes of $100 \mathrm{mM}$ ammonium acetate in methanol overnight at $-20^{\circ} \mathrm{C}$. The pellets were rinsed three times with ice-cold acetone containing $13 \mathrm{mM}$ DTT and then lyophilized. The resulting pellets were dissolved in a sample buffer (7 M urea, $2 \mathrm{M}$ thiourea, 4\% (w/v) CHAPS, 2\% (v/v) Ampholine pH 3.5-10, 1\% $(\mathrm{w} / \mathrm{v})$ DTT) at room temperature. Two-dimensional electrophoresis was carried out according to Yang et al. (2007). The isoelectrofocusing (IEF) gels were $15 \mathrm{~cm}$ long with a diameter of $3 \mathrm{~mm}$. The gel solution contains $8 \mathrm{M}$ urea, 3.6\% (w/v) acrylamide, 2\% NP-40 and 5\% (v/v) Ampholines (1 part pH 3.5-10, 1 part pH 5-8). For each gel, $50 \mu \mathrm{l}$ sample was loaded. IEF was performed at $200 \mathrm{~V}, 400 \mathrm{~V}$ and $800 \mathrm{~V}$ for $30 \mathrm{~min}, 15 \mathrm{~h}$ and $1 \mathrm{~h}$ respectively. After the IEF run, IEF gels were equilibrated in equilibration buffer (62.5 mM Tris- $\mathrm{HCl}$ pH 6.8, 2.5\% SDS, 10\% (v/v) glycerol and $5 \%(\mathrm{v} / \mathrm{v}) 2$-mercaptoethanol for $15 \mathrm{~min}$ twice. For the second dimension, the proteins were separated on $15 \%$ SDS polyacrylamide gels. Protein spots were visualized with Coomassie Brilliant Blue (CBB) R-250.

\section{Image and data analysis}

The 2-DE gels were scanned at a 600 dots per inch (dpi) resolution with UMAX Power Look 2100XL scanner (Maxium Tech, inc., Taiwan, China). The transparency mode was used to obtain a grayscale image. The image analysis was performed with ImageMaster ${ }^{\mathrm{TM}}$ 2D Platinum version 5.0 (GE Healthcare BIO-Science). The optimized parameters were as follows: saliency 2.0, partial threshold 4 and minimum area 50. Spots were quantified on the basis of their relative volume $(\% \mathrm{~V})$, which was determined by the ratio of the volume of a single spot to the whole set of spots. Only those with reproducible changes (quantitative changes more than 1.5-fold in abundance and $\mathrm{t}$ - test $\mathrm{P}<$ $0.05)$ among three replicates were used for further analysis.

\section{In-gel digestion and MALDI-TOF MS analysis}

Protein spots were manually excised from the gel, and in-gel digestion by trypsin was performed according to Wang et al. (2009a) with some modifications. Gel slices were washed with $25 \%(\mathrm{v} / \mathrm{v})$ ethanol and $7 \%(\mathrm{v} / \mathrm{v})$ acetic acid for $12 \mathrm{~h}$ overnight at room temperature, and 
destained with $50 \mathrm{mM} \mathrm{NH}_{4} \mathrm{HCO}_{3}$ in $50 \%(\mathrm{v} / \mathrm{v})$ methanol for $1 \mathrm{~h}$ at $40^{\circ} \mathrm{C}$. Proteins were reduced with $10 \mathrm{mM}$ DTT in $100 \mathrm{mM} \mathrm{NH} \mathrm{HCO}_{3}$ for $1 \mathrm{~h}$ at $60^{\circ} \mathrm{C}$, and alkylated with $40 \mathrm{mM}$ iodoacetamide in $100 \mathrm{mM}$ $\mathrm{NH}_{4} \mathrm{HCO}_{3}$ for $30 \mathrm{~min}$ at room temperature in the dark. The gel pieces were minced and lyophilized, then digested with $10 \mathrm{ng}$ sequencing-grade modified trypsin in $25 \mathrm{mM} \mathrm{NH} \mathrm{HCO}_{3}$ solution overnight at $37^{\circ} \mathrm{C}$. After digestion, the peptides were collected, and the pellets were washed with $0.1 \%$ TFA in $50 \% \mathrm{v} / \mathrm{v}$ acetonitrile three times to collect the remaining peptides. The solution containing eluted peptides was desalted by ZipTipC $18 \mathrm{P}^{\mathrm{mix}}$.

Tryptic peptide masses were measured with an AXIMA-CFR plus MALDI-TOF mass spectrometry (Shimadzu Biotech, Kyoto, Japan). The acquired peptidemass fingerprints (PMFs) were analyzed by searching NCBI database with the Mascot software available at (http://www.matrixscience.com). The searching parameters were set according to Yang et al. (2007). O. sativa was chosen for the taxonomic category and 0.2 Da was used as the mass error tolerance. To determine the confidence of the identification results, the following criteria were used: a minimum MOWSE score was 66 , and sequence coverage of the protein should not be less than $12 \%$ by the matching peptides. Only the best matches with high confidence levels were selected.

\section{Real-time quantitative RT-PCR}

Real-time quantitative RT-PCR was carried out as previously described (Wang et al. 2009b). Total RNA was extracted using the RNA PCR kit (Takara Bio, Otsu, Japan), and treated with DNAse-I (Ambion, Austin, TX), according to the manufacturer's instructions. First strand cDNA was synthesized using the SMART PCR cDNA Synthesis Kit (BD Biosciences) according to the manufacturer's instructions. The $O$. sativa $18 \mathrm{~S}$ rDNA gene was used as a standard to normalize the content of cDNA. PCR was performed using gene-specific primers (Additional file 1: Table S1) on a Rotor Gene 3000 Real-Time Thermal Cycler (Corbet Research, Sydney, Australia). SYBR Premix Ex Taq (Perfect Real Time) kit and RT-PCR reagents (Takara Bio) were used for quantification of differentially expressed gene sequences.

\section{Additional file}

Additional file 1: Table S1. Primer pairs used in Quantitative Real-Time PCR.

\section{Abbreviations}

CBB: Coomassie Brilliant Blue; CDC: Cell division cycle proteins; CDKs: Cyclins and cyclin-dependent kinases; 2-DE: Two-dimensional gel electrophoresis;

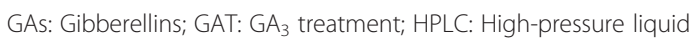
chromatography; IEF: Isoelectrofocusing; MMSDH: Methylmalonatesemialdehyde dehydrogenase; PMFs: Peptide-mass fingerprints.

\section{Competing interests}

The authors declare that they have no competing interests.

\section{Authors' contributions}

XQW designed research, performed experiments, analyzed data, and wrote the manuscript. FH performed experiments and analyzed data. MFY analyzed data. PFY analyzed data. SHS designed research. All authors read and approved the final manuscript.

\section{Acknowledgments}

This work was supported by grants from Beijing Natural Science Foundation (No. 5132004), National Natural Science Foundation of China (No. 30970250), Beijing University of Agriculture Improving Research Quality Foundation (No. GL2012001) to Dr. Wang, and grant from National Program on Key Basic Research Project (973 Program, 2010CB126503) to Dr. Shen.

\section{Author details}

${ }^{1}$ Key Laboratory of Urban Agriculture (North) Ministry of Agriculture, Beijing University of Agriculture, Beijing 102206, China. ${ }^{2}$ Institute of Botany, Chinese Academy of Sciences, Beijing 100093, China. ${ }^{3}$ College of Life Sciences,

Northwest A\&F University, Yangling 712100, China. ${ }^{4}$ Wuhan Botanical Garden, Chinese Academy of Sciences, Wuhan 430074, China.

Received: 18 February 2013 Accepted: 18 June 2013

Published: 1 July 2013

\section{References}

Arnon DI (1949) Copper enzymes in islated chlroplasts polyphenoxidase in Beta vulgaris. Plant Physiol 24:1-15

Avery GS Jr (1993) Structure and development of the tobacco leaf. Amer J Bot 20:565-592

Beach D, Durkacz B, Nurse P (1982) Functionally homologous cell cycle control genes in budding and fission yeast. Nature 300:706-709

Beemster GT, Fiorani F, Inze D (2003) Cell cycle: the key to plant growth control? Trends Plant Sci 8:154-158

Bevan M, Bancroft I, Bent E, Love K, Goodman H, Dean C, Bergkamp R, Dirkse W, Van Staveren M, Stiekema W, Drost L, Ridley P, Hudson SA, Patel K, Murphy G, Piffanelli P, Wedler H, Wedler E, Wambutt R, Weitzenegger T, Pohl TM, Terny N, Gielen J, Villarroel R, De Clerck R, Van Montagu M, Lecharny A, Auborg S, Gy I, Kreis M et al (1998) Analysis of $1.9 \mathrm{Mb}$ of contiguous sequence from chromosome 4 of Arabidopsis thaliana. Nature 391:485-488

Boston RS, Viitanen PV, Vierling E (1996) Molecular chaperones and protein folding in plants. Plant Mol Biol 32:191-222

Buchberger A (2010) Control of ubiquitin conjugation by cdc48 and its cofactors. Subcell Biochem 54:17-30

Cai H, Wang CC, Tsou CL (1994) Chaperone-like activity of protein disulfide isomerase in the refolding of a protein with no disulfide bonds. J Biol Chem 269:24550-24552

Cheeseman IM, Desai A (2004) Cell division: AAAtacking the mitotic spindle. Curr Biol 14:R70-R72

Chen FM (1984) Determining the chlorophyll contents of plant leaves by acetone/ethanol mixture assay. Forestry Sci Communic 2:4-8

Cosgrove DJ, Sovonick-Dunford SA (1989) Mechanism of gibberellin-dependent stem elongation in peas. Plant Physiol 89:184-191

Davies PJ (1995) Plant hormones: physiology, biochemistry and molecular biology. Kluwer Academic publisher, Dordrecht, The Netherlands

Dijkstra P, Reegen H, Kuiper PJ (1990) Relation between relative growth rate, endogenous gibberellins, and the response to applied gibberellic acid for Plantago major. Physiol Plant 79:629-634

Fleming AJ (2006) The co-ordination of cell division, differentiation and morphogenesis in the shoot apical meristem: a perspective. J Exp Bot 57:25-32

Freedman RB (1984) Native disulfide bond formation in proteinbiosynthesisevidence for the role of protein disulfide isomerase. Trends Biochem Sci 9:438-441

Fry SC (1998) Oxidative scission of plant cell wall polysaccharides by ascorbateinduced hydroxyl radicals. Biochem J 332(Pt 2):507-515 
Fu Q, Wang BC, Jin X, Li HB, Han P, Wei KH, Zhang XM, Zhu YX (2005) Proteomic analysis and extensive protein identification from dry, germinating Arabidopsis seeds and young seedlings. J Biochem Mol Biol 38:650-660

Gazzarrini S, McCourt P (2003) Cross-talk in plant hormone signalling: what Arabidopsis mutants are telling us. Ann Bot 91:605-612

Haag-Kerwer A, Schäfer HJ, Heiss S, Walter C, Rausch T (1999) Cadmium exposure in Brassica juncea causes a decline in transpiration rate and leaf expansion without effect on photosynthesis. J Exp Bot 50:1827-1835

Haber AH, Tolbert NE (1957) Photosynthesis in Gibberellin-Treated Leaves. Plant Physiol 32:152-153

Hartl FU (1996) Molecular chaperones in cellular protein folding. Nature 381:571-579

Hong SW, Jon JH, Kwak JM, Nam HG (1997) Identification of a receptor-like protein kinase gene rapidly induced by abscisic acid, dehydration, high salt, and cold treatments in Arabidopsis thaliana. Plant Physiol 113:1203-1212

Inze D, De Veylder L (2006) Cell cycle regulation in plant development. Annu Rev Genet 40:77-105

Kaiser P, Flick K, Wittenberg C, Reed SI (2000) Regulation of transcription by ubiquitination without proteolysis: Cdc34/SCF(Met30)-mediated inactivation of the transcription factor Met4. Cell 102:303-314

Kelen M, Demiralay EC, Sen S, OZKAN G (2004) Separation of Abscisic Acid, Indole-3-Acetic Acid, Gibberellic Acid in 99 R (Vitis berlandieri x Vitis rupestris) and Rose Oil (Rosa damascena Mill.) by Reversed Phase Liquid Chromatography. Turk J Chem 28:603-610

King RW, Deshaies RJ, Peters JM, Kirschner MW (1996) How proteolysis drives the cell cycle. Science 274:1652-1659

Komatsu S, Zang X, Tanaka N (2006) Comparison of two proteomics techniques used to identify proteins regulated by gibberellin in rice. J Proteome Res 5:270-276

Lessard P, Bouly JP, Jouannic S, Kreis M, Thomas M (1999) Identification of cdc2cAt: a new cyclin-dependent kinase expressed in Arabidopsis thaliana flowers. Biochim Biophys Acta 1445:351-358

Meijer M, Murray JA (2001) Cell cycle controls and the development of plant form. Curr Opin Plant Biol 4:44-49

Morgan DO (1995) Principles of CDK regulation. Nature 374:131-134

Nakajima M, Shimada A, Takashi Y, Kim YC, Park SH, Ueguchi-Tanaka M, Suzuki H, Katoh E, luchi S, Kobayashi M, Maeda T, Matsuoka M, Yamaguchi I (2006) Identification and characterization of Arabidopsis gibberellin receptors. Plant J 46:880-889

Park S, Rancour DM, Bednarek SY (2008) In planta analysis of the cell cycledependent localization of AtCDC48A and its critical roles in cell division, expansion, and differentiation. Plant Physiol 148:246-258

Pellinen RI, Korhonen MS, Tauriainen AA, Palva ET, Kangasjarvi J (2002) Hydrogen peroxide activates cell death and defense gene expression in birch. Plant Physiol 130:549-560

Rancour DM, Park S, Knight SD, Bednarek SY (2004) Plant UBX domain-containing protein 1, PUX1, regulates the oligomeric structure and activity of arabidopsis CDC48. J Biol Chem 279:54264-54274

Shen S, Sharma A, Komatsu S (2003) Characterization of proteins responsive to gibberellin in the leaf-sheath of rice (Oryza sativa L.) seedling using proteome analysis. Biol Pharm Bull 26:129-136

Tanaka N, Konishi H, Khan MMK, Komatsu S (2004) Proteome analysis of rice tissues by two-dimensional electrophoresis: an approach to the investigation of gibberellin regulated proteins. Mol Genet Genomics 270:485-496

Tanaka N, Takahashi H, Kitano H, Matsuoka M, Akao S, Uchimiya H, Komatsu S (2005) Proteome approach to characterize the methylmalonatesemialdehyde dehydrogenase that is regulated by gibberellin. J Proteome Res 4:1575-1582

Thetford M, Warren SL, Blazich FA, Thomas JF (1995) Response of Forsythia-X intermedia 'Spectabilis' to uniconazole. II. Leaf and stem anatomy, chlorophyll, and photosynthesis. J Am Soc Hortic Sci 120:983-988

Ueguchi-Tanaka M, Ashikari M, Nakajima M, Itoh H, Katoh E, Kobayashi M, Chow TY, Hsing Yl, Kitano H, Yamaguchi I, Matsuoka M (2005) GIBBERELLIN INSENSITIVE DWARF1 encodes a soluble receptor for gibberellin. Nature 437:693-698

Vernoux T, Autran D, Traas J (2000) Developmental control of cell division patterns in the shoot apex. Plant Mol Biol 43:569-581

Wang XQ, Yang PF, Liu Z, Liu WZ, Hu Y, Chen H, Kuang TY, Pei ZM, Shen SH, He YK (2009a) Exploring the mechanism of Physcomitrella patens desiccation tolerance through a proteomic strategy. Plant Physiol 149:1739-1750
Wang W, Vinocur B, Shoseyov O, Altman A (2004) Role of plant heat-shock proteins and molecular chaperones in the abiotic stress response. Trends Plant Sci 9:244-252

Wang XQ, Yang PF, Liu Z, Liu WZ, Hu Y, Chen H, Kuang TY, Pei ZM, Shen SH, He YK (2009b) Exploring the mechanism of Physcomitrella patens desiccation tolerance through a proteomic strategy. Plant Physiol 149:1739-1750

Yang G, Inoue A, Takasaki H, Kaku H, Akao S, Komatsu S (2005) A proteomic approach to analyze auxin- and zinc-responsive protein in rice. J Proteome Res 4:456-463

Yang GX, Jan A, Shen SH, Yazaki J, Ishikawa M, Shimatani Z, Kishimoto N, Kikuchi S, Matsumoto H, Komatsu S (2004) Microarray analysis of brassinosteroidsand gibberellin-regulated gene expression in rice seedlings. Mol Genet Genomics 271:468-478

Yang P, Chen H, Liang Y, Shen S (2007) Proteomic analysis of de-etiolated rice seedlings upon exposure to light. Proteomics 7:2459-2468

Yang T, Davies PJ, Reid JB (1996) Genetic Dissection of the Relative Roles of Auxin and Gibberellin in the Regulation of Stem Elongation in Intact LightGrown Peas. Plant Physiol 110:1029-1034

Yazaki J, Kishimoto N, Nagata Y, Ishikawa M, Fujii F, Hashimoto A, Shimbo K, Shimatani Z, Kojima K, Suzuki K, Yamamoto M, Honda S, Endo A, Yoshida Y, Sato Y, Takeuchi K, Toyoshima K, Miyamoto C, Wu J, Sasaki T, Sakata K, Yamamoto K, Iba K, Oda T, Otomo Y, Murakami K, Matsubara K, Kawai J, Carninci P, Hayashizaki $Y$ et al (2003) Genomics approach to abscisic acidand gibberellin-responsive genes in rice. DNA Res 10:249-261

doi:10.1186/1939-8433-6-17

Cite this article as: Wang et al:: Exploring the response of rice (Oryza sativa) leaf to gibberellins: a proteomic strategy. Rice 2013 6:17.

\section{Submit your manuscript to a SpringerOpen ${ }^{\odot}$ journal and benefit from:}

- Convenient online submission

Rigorous peer review

- Immediate publication on acceptance

- Open access: articles freely available online

- High visibility within the field

- Retaining the copyright to your article

Submit your next manuscript at springeropen.com 